\title{
Der Teufel und seine poietische Macht
}

\author{
Eine Einführung
}

\section{Der Teufel - eine produktive Störfigur}

„Der Teufel ist die Verkörperung des Bösen. Sein Ziel liegt darin, den Menschen zur Sünde zu verleiten. Um dies zu erreichen, spricht er mit gespaltener Zunge, versucht sein Gegenüber zu verführen und stiftet es an, sich verschiedenen Lastern hinzugeben. Er versteckt sich hinter einer unüberschaubaren Anzahl von Masken, die er - der Situation und seinem jeweiligen Ziel gemäß - aufsetzt, um die Menschen zu verblenden, sie durch Illusionen zu täuschen und in Angst und Schrecken zu versetzen. Der Teufel versucht, die Menschen ins Verderben zu stürzen und zu sich in die Hölle zu locken; wenn er damit erfolgreich ist, bleibt nichts von dem, was er vorfindet, intakt. Als gefallener Engel versucht er aus Neid, den Menschen ihren Platz zur Rechten Gottes streitig zu machen.“

So oder so ähnlich könnte ein in der abendländisch-christlichen Vormoderne entworfener Steckbrief des Teufels aussehen, und ähnliche Charakteristika hat die geistes- und kulturwissenschaftliche Forschung bisher mehrheitlich adressiert, wenn sie sich mit dem Teufel auseinandersetzte. Doch wird versuchsweise von der theologisch begründeten Dichotomie zwischen Gut und Böse abgesehen, welche die Aufmerksamkeit überwiegend auf die destruktiven und boshaften Eigenschaften des Teufels lenkt, könnte die Beschreibung derselben Tätigkeiten und somit das Profil der Figur auch ganz anders ausfallen:

„Der Teufel kann sich als körperlose, aber wesenhafte Existenz den Menschen in unendlich vielen Gestalten zugesellen und so zu ihrem flexiblen Interaktionspartner werden. Dabei versteht er es, intellektuell anspruchsvoll, rhetorisch versiert und mit feinem Sensorium für emotionale Bedürnnisse und individuelle Dispositionen zu agieren. Er eröffnet den Menschen neue Perspektiven und Entscheidungsmöglichkeiten und gibt ihnen so die Gelegenheit, sich ihres freien Willens bewusst zu werden. Er provoziert sein Gegenüber, in sich hineinzuhorchen, verborgene Sehnsüchte zu entdecken und gegebenenfalls auszule-

Jutta Eming, Freie Universität Berlin, Institut für Deutsche und Niederländische Philologie, Habelschwerdter Allee 45, 14195 Berlin, j.eming@fu-berlin.de

Daniela Fuhrmann, Universität Zürich, Deutsches Seminar, Schönberggasse 9, CH-8001

Zürich, daniela.fuhrmann@uzh.ch

Ә Open Access. ( 2021 Jutta Eming, Daniela Fuhrmann, publiziert von De Gruyter. (cc) BY-NC-ND Dieses Werk ist lizensiert unter einer Creative Commons Namensnennung - Nicht-kommerziell - Keine Bearbeitung 4.0 International Lizenz.

https://doi.org/10.1515/9783110667189-001 
ben. In seinem Auftreten ist der Teufel facettenreich, anpassungsfähig und äußerst unterhaltsam, sein Einfallsreichtum und seine non-konforme Versatilität versetzen ihn zudem in die Lage, sakrosankte Strukturen und Ordnungen aufzubrechen und Wege in Neuland zu weisen.“

Das Steckbrief-Experiment wird offensichtlich von folgenden Fragen geleitet: Welche Auswirkungen hat es für das Verständnis einer paradigmatischen Figur der Kultur der Vormoderne, wenn moralische Implikationen beiseitegelassen und stattdessen ihre produktiven Potentiale fokussiert werden? Inwiefern kann der Teufel als Generator von Individualität, Vermittler neuen Wissens oder Sprengmeister überkommener Ordnungen und Konventionen kulturevolutionäres Potential für sich reklamieren, das in historisch-anthropologischer, epistemologischer oder ästhetischer Hinsicht weiter zu verfolgen wäre? Wie wäre die bisherige Literatur- wie Kulturgeschichte des Teufels durch eine derartige Perspektivierung dann zu modifizieren?

Der vorliegende Band versteht sich als ein Schritt auf dem Weg, der forschungsgeschichtlichen ,Verteufelung des Teufels' in der skizzierten Weise zu begegnen. Er geht von dem Befund aus, dass die in vormoderner Literatur auftretende Teufelsfigur sowie an diese gebundene diabolische Wesen überwiegend in ihrem antagonistischen, den Weg zu Gott verstellenden und das Gute zerstörenden Charakter wahrgenommen werden. Ohne die negative Seite der Figur zu ignorieren, suchen die hier versammelten Beiträge eine alternative Annäherung an den Teufel. Sie gehen von der Hypothese aus, dass die etablierte, primär theologisch-moralische Lesart des Teufels immer noch den Blick auf viele schöpferische und gestalterische Eigenschaften der Figur verstellt, die produktiv auf ästhetische Form und Sinnstiftung eines Textes einwirken können. Vielleicht wird das vielgestaltige, oft detailliert ausspekulierte Auftreten des Teufels in vormoderner Literatur sogar eher aus den produktiven als aus den destruktiven Facetten der Figur erklärlich. Zu fragen wäre also, was der Teufel - trotz oder gerade wegen seiner non-konformen Bosheit - als Figur im Text zu leisten in der Lage ist, worin sich sein Aktionsfeld, seine Handlungsweise und kommunikative Kompetenz von denjenigen anderer Figuren unterscheiden mögen. Wozu ermächtigt der Einsatz eines Teufels im Text? Welcher ästhetische Möglichkeitsraum eröffnet sich um die diabolische Figur herum, aus dem literarische Texte ihre Gestaltungs-, Deutungs- und Sinnbildungspotentiale schöpfen können?

Die Herausgeberinnen dieses Bandes fassen die produktiven Eigenschaften des Teufels als seine poietische Kraft oder Poiesis, und zwar sowohl im weiteren Sinne als Form des herstellenden Handelns als auch im engeren Sinne 
als Dichtung. Sie interessieren sich, der Begriffstradition folgend, insbesondere für solche poietischen Tendenzen, die Ästhetik und Eigenständigkeit des künstlerischen Prozesses Geltung verschaffen. Die Adressierung des Teufels (als Figur) erfolgt dabei mit dem Bewusstsein, ihn - gerade für die Vormoderne - nicht einfach als fiktionale Gestalt verstehen zu können. ${ }^{1}$ Was sich auf der Ebene der literarischen und bildkünstlerischen Werke meist figürlich realisiert - sei es im Auftreten ,des` Teufels als einer einzelnen Figur oder im Verbund mit einer ganzen Gruppe von Co-Teufeln oder dämonischen Wesen -, ist Ausdruck eines kulturellen Konzepts. ${ }^{2}$ Die jeweilige ,Figur des Teufels‘ im Text repräsentiert in ihrer individuellen Ausgestaltung ausgewählte Aspekte dieses Konzepts, überführt sie in eine konkrete Anschaulichkeit und ermöglicht es so, sich reflektierend, evaluierend, kritisierend oder auch konstruierend mit der ,Idee Teufel' über den Weg der literarischen Figur auseinanderzusetzen.

Die Beiträge dieses Bandes nehmen eben diese literarischen Teufelsfiguren als Ausgangspunkt ihrer Analysen und widmen sich in detaillierter Auseinandersetzung mit ausgewählten Quellen unterschiedlichen Nuancen der hier kurz skizzierten poietischen Macht des Teufels. Sie beschreiben und charakterisieren das Auftreten von Teufelsfiguren in einer Bandbreite von literarischen Genres: (höfischen) Legenden (MÜLlER, NowAKOwSKI, TsCHACHTLI), heldenepischer Erzählung (TRAULSEN), geistlichem Spiel (EMING), Prosa-, Barockroman (Bergengruen, Fuhrmann, Wei) und modernem Roman (Brittnacher). Dabei identifizieren sie poietisch wirksam werdende Potentiale des Teufels, die sich dezidiert mit ihm als einer produktiven Störfigur verbinden, mitunter aber auch abgelöst, als nur mehr diabolische Textstrategien realisiert werden können (BERGENGRUEN, BRITTNACHER).

1 Vgl. dazu den Überblick bei TiLl, Dietmar: [Art.] Poiesis. In: RL III, Berlin, New York 2007, S. 113-115.

2 Vgl. SChnierer, Peter Paul: Entdämonisierung und Verteufelung. Studien zur Darstellungsund Funktionsgeschichte des Diabolischen in der englischen Literatur seit der Renaissance, Tübingen 2005 (Studien zur englischen Philologie 37), S. 15; BocKMANN, Jörn/GoLD, Julia: Kommunikation mit Teufeln und Dämonen. In: Turpiloquium. Kommunikation mit Teufeln und Dämonen in Mittelalter und Früher Neuzeit. Hrsg. von DENS., Würzburg 2017 (Würzburger Beiträge zur deutschen Philologie 41), S. 1-18, hier S. 9, mit Bezug auf RuSSELL, Jeffrey Burton: Lucifer. The Devil in the Middle Ages, Ithaca, London 1984, S. 12. So auch FLASCH, Kurt: Der Teufel und seine Engel. Die neue Biographie, München ${ }^{2} 2016$, S. 61, der zudem deutlich darauf hinweist, dass hinter dem Teufel ein ,zeitgeprägtes soziales Phänomen, kein zeitloser Archetypus“ (S. 49) stehe; siehe zum Konzept ,Teufel‘ außerdem ebd., S. 68-70. 


\section{Der Teufel: Forschungsgegenstand und Faszinosum}

Füttert man die Suchmaschine der Forschungsdatenbanken einzig mit dem Begriff ,Teufel', resultiert die Recherche in einem umfangreichen Angebot an Kulturgeschichten der Figur. ${ }^{3}$ Die Mehrheit dieser Überblickswerke nimmt die diachrone Entwicklung des Teufels in den Blick, der - zumindest in der christlich-abendländischen Tradition - seine Karriere auf religiösem Terrain begann, seinen Einfluss jedoch schnell auch auf andere Bereiche des sozio-kulturellen Lebens ausdehnen konnte. Im Alten Testament erscheint der Teufel, etwa als Satan im Buch Hiob, noch als eine Figur, die keineswegs in bloßer Zerstörungswut auf die göttliche Schöpfung oder aus purem Antagonismus agiert, sondern vielmehr als Handlanger Gottes, um Hiobs Gottesfurcht unter Beweis zu stellen (vgl. Hiob 1,9-11) ${ }^{4}$ und somit die göttliche Ordnung zu bestätigen. Satan trägt keine Züge eines Verführers oder Betrügers, er ist weder ausgesprochen bösartig noch auffällig destruktiv, sondern sticht am ehesten durch Eloquenz, Gewandtheit und Intelligenz unter anderen dämonischen Wesen hervor. ${ }^{5}$ Es sind erst die Erzählungen des Neuen Testaments (etwa Mt 4,1-11 sowie Mk 4,1-13) wie auch die teils von paganen Einflüssen bestimmte patristische Exegese, ${ }^{6}$ die den Teufel zu einem lebendigen Widersacher Gottes und des Menschen ausgestalten. ${ }^{7}$ Die damit einhergehende Ausweitung des Aktionsradius Satans im

\footnotetext{
3 Siehe beispielsweise Roskoff, Gustav: Geschichte des Teufels. Eine kulturhistorische Satanologie von den Anfängen bis ins 18. Jahrhundert, Leipzig 1869 (Nachdruck Nördlingen 1987); RussELL, Jeffrey Burton: The Devil: Perceptions of Evil from Antiquity to Primitive Christianity, Ithaca, London 1977; DERS.: Lucifer (Anm. 2); DERS.: The Prince of Darkness. Radical Evil and the Power of Good in History, Ithaca, New York 1988; DERS.: The Historical Satan. In: The Satanism Scare. Social Institutions and Social Change. Hrsg. von James T. Richardson/Joel BeSt/David G. BROMLEY, New York 1991, S. 41-48; MAHAL, Günther: Der Teufel. Anmerkungen zu einem nicht allein mittelalterlichen Komplex. In: Dämonen, Monster, Fabelwesen. Hrsg. von Ulrich MÜLLER/Werner WunDERLICH, St. Gallen 1999 (Mittelalter Mythen 2), S. 495-531; FlaSCH, Der Teufel (Anm. 2); GoETZ, Hans-Werner: Gott und die Welt. Religiöse Vorstellungen des frühen und hohen Mittelalters. Teil I, Band 3, IV. Engel, Teufel, Menschen, Göttingen 2016 (Orbis mediaevalis 16).

4 Vgl. hier und im Folgenden die Neue Einheitsübersetzung (https://www.die-bibel.de/bibeln /online-bibeln/einheitsuebersetzung/bibeltext/?no_cache=1bibeltext $\% 2$ Fbibel\%2Ftext $\% 2$ Fle sen\%2Fstelle\%2F2\%2F10001\%2F19999\%2F; Zugriff: 06. Juni 2020).

5 Vgl. HamoRi, Esther J.: Reflection. The Early History of Satan: Before the satan was Evil. In: Evil. A History. Hrsg. von Andrew P. CHIGNELL, New York 2019, S. 82-87.

6 Vgl. Roskoff, Geschichte des Teufels, S. 190-199 (Anm. 3).

7 Vgl. MaHAL, Der Teufel, S. 498/499 (Anm. 3).
} 
Neuen Testament, insbesondere die kulturell einflussreiche Offenbarung des Johannes und die theologische Beschäftigung mit dem Teufel in Patristik und Scholastik bis mindestens zu Luther legen den Grundstein für die charakteristische Vielgestaltigkeit der Figur. ${ }^{8}$ Vor allem das Profil als Repräsentant der mannigfaltigen Gestaltwerdungen des Bösen sollte sich durchsetzen - sowohl im vormodernen Europa als auch in dessen kulturgeschichtlicher Erforschung; so zumindest legen es viele ältere und neuere Publikationen zum Teufel nahe. ${ }^{9}$ Buchtitel wie „Teufel, Satan, Luzifer. Universalgeschichte des Bösen“10 , „The Devil. Perceptions of the Evil from Antiquity to Primitive Christianity“11 oder „Das Böse, Teufel und Dämonen“12 erwecken den Eindruck, als werde der Teufel dabei auf seine destruktiven Potentiale festgelegt. Auch wenn eine Vielzahl der Veröffentlichungen zugleich das proteische Wesen des Teufels registriert, ${ }^{13}$ tritt dieses Merkmal als offenbar benötigtes Mittel hinter den Zweck, das Ausleben und Säen des Bösen, zurück. Dabei deutet sich im Forschungskonsens, dass der „Teufel als ,Tausendkünstler،“14 jede beliebige Erscheinung annehmen könne, um seine heimtückische Verführungskunst auszuüben und seine niederträchtigen Ziele zu verfolgen, bereits eine gewisse poietische Macht an: Begreift man die facettenreich schillernde Gestalt des Teufels in der Vormoderne als kulturelle Konstruktion, als Projektionsfläche für Ängste, Bedrohungen oder reizvolle Versuchungen, dann können die individuellen Ausgestaltungen der Figur als Beleg für vielfältige Imaginationsleistungen sowie folglich

8 Vgl. insbesondere die Kapitel III-X bei Flasch, Der Teufel (Anm. 2).

9 Siehe beispielsweise CoRTÉ, Nicolas: Unser Widersacher der Teufel. Der Christ in der Welt, Aschaffenburg 1957 (Die großen Wahrheiten 5); Russell, The Devil (Anm. 3); MASLOwsKI, Peter: Das theologische Untier. Der sogenannte Teufel und seine Geschichte im Christentum, Berlin 1978 (InterReihe 1); Russel, The Prince of Darkness (Anm. 3); HAUG, Walter: Der Teufel und das Böse im mittelalterlichen Roman. In: Seminar. A Journal of Germanic Studies 21/3 (1985), S. 165-191; GRÜBEL, Isabel: Die Hierarchie der Teufel. Studien zum christlichen Teufelsbild und zur Allegorisierung des Bösen in Theologie, Literatur und Kunst zwischen Frühmittelalter und Gegenreformation, München 1991 (Kulturgeschichtliche Forschungen 13); MESSADIÉ, Gerald: Teufel, Satan, Luzifer. Universalgeschichte des Bösen, Frankfurt a. M. 1995; Evil and Devil. Hrsg. von Ida FRöHLICH/Erkki Kostenniemi, London, New York 2013; Das Böse, der Teufel und Dämonen/Evil, the Devil and Demons. Hrsg. von Jan DochHoRn/Susanne RudNIG-Zelt/Benjamin Wold, Tübingen 2016 (Wissenschaftliche Untersuchungen zum Neuen Testament 412).

10 Messadié, Teufel, Satan, Luzifer (Anm. 9).

11 Russell, The Devil (Anm. 3).

12 DochHorn/Rudnig-Zelt/Wold, Das Böse (Anm. 9).

13 Siehe etwa Mahal, Der Teufel, S. 520/521 (Anm. 3); Schumacher, Meinolf: Der Teufel als ,Tausendkünstler‘. Ein wortgeschichtlicher Beitrag. In: Mittellateinisches Jahrbuch 27 (1993), S. 65-76; SCHNIERER, Entdämonisierung, bes. S. 4 (Anm. 2).

14 Schumacher, Der Teufel als ,Tausendkünstler‘, S. 65 (Anm. 13). 
ein kreatives Potential gelten, das sich offenbar mit dem Teufel verknüpft. Er stimuliert - was alle im Folgenden besprochenen Romane, Kurzerzählungen und Dramentexte exemplarisch illustrieren - die literarische Einbildungskraft ${ }^{15}$ und provoziert anspruchsvolle Erzeugnisse sowohl im literarischen wie bildkünstlerischen Bereich. ${ }^{16}$

Die Germanistik hat sich in den vergangenen Jahrzehnten vielfach mit dem Teufel auseinandergesetzt. Unter den Arbeiten finden sich Studien, die eher synthetisch angelegt sind, ${ }^{17}$ ebenso wie Einzelanalysen: zu speziellen Gattungen wie beispielsweise dem geistlichen Spiel ${ }^{18}$ oder der Paarreimdichtung ${ }^{19}$; zu speziellen teuflischen Eigenschaften wie seiner Bosheit/Boshaftigkeit ${ }^{20}$; zu ausgewiesenen Handlungsweisen wie dem Teufelspakt ${ }^{21}$ oder spezifisch diabolischen

15 Vgl. Haug, Der Teufel und das Böse, S. 185-187 (Anm. 9); MAHAL, Der Teufel, S. 518 (Anm. 3); BocKMAnN/GolD, S. 6 (Anm. 2). Vgl. demnächst außerdem EmING, Jutta: Dämonische Verführung. Zur Figur des Teufels und ihrer literarischen Produktivität im Mittelalter. In: Akten des Kulturseminars. Hrsg. von der Japanischen Gesellschaft für Germanistik [erscheint online 2020].

16 Für kunsthistorische Arbeiten siehe beispielsweise ScHADE, Herbert: Dämonen und Monstren. Gestaltung des Bösen in der Kunst des Frühen Mittelalters, Regensburg 1962; MetTernich, Wolfgang: Teufel, Geister und Dämonen. Das Unheimliche in der Kunst des Mittelalters, Darmstadt 2011, bes. S. 33-53 (III. Der Fürst der Hölle; IV. Die unheimliche Schar der Dämonen); ARASSE, Daniel: Bildnisse des Teufels. Mit einem Essay von Georges Bataille, Berlin 2012; Angelus \& Diabolus. Engel, Teufel und Dämonen in der christlichen Kunst. Hrsg. von Rolf Toman, Berlin 2016.

17 Vgl. beispielsweise SPREITZER, Brigitte: ,Wie bist Du vom Himmel gefallen?‘ Einschlagstellen des Diabolischen in der Literatur des späteren Mittelalters, Wien u. a. 1995 (Fazit 1); demnächst außerdem: BockMANN, Jörn: Figuren des Diabolischen. Studien zur niederdeutschen Erzählliteratur des Mittelalters, Berlin, Boston 2020 (Quellen und Forschungen zur Literatur- und Kulturgeschichte 80 [314]) [im Druck].

18 Vgl. Schuldes, Luis: Die Teufelsszenen im deutschen geistlichen Drama des Mittelalters. Versuch einer literarhistorischen Betrachtung unter besonderer Betonung der geistesgeschichtlichen Gesichtspunkte, Göppingen 1974 (Göppinger Arbeiten zur Germanistik 116); UKENA-BEST, Elke: Homud heft us duvele senket in afgrunde. Superbia, Teufel und Hölle im Redentiner Osterspiel. In: Leuvense Bijdragen 90 (2001), S. 181-214.

19 Vgl. beispielsweise SLENCZKA, Alwine: Mittelhochdeutsche Verserzählungen mit Gästen aus Himmel und Hölle. Münster u. a. 2004 (Studien und Texte zum Mittelalter und zur frühen Neuzeit 5).

20 Siehe z. B. HAUG, Der Teufel und das Böse (Anm. 9), oder BRÜGGEMAnN, Romy: Die Angst vor dem Bösen. Codierungen des malum in der spätmittelalterlichen und frühneuzeitlichen Narren-, Teufel- und Teufelsbündnerliteratur, Würzburg 2010 (Epistemata Literaturwissenschaft 685).

21 Etwa bei HAUG, Walter: Der Teufelspakt vor Goethe oder Wie der Umgang mit dem Bösen als felix culpa zu Beginn der Neuzeit in die Krise gerät. In: DVjS 75/2 (2001), S. 185-215; HILLE, Iris: Der Teufelspakt in den frühneuzeitlichen Verhörprotokollen. Standardisierung und Regionalisierung im Frühneuhochdeutschen, Berlin, New York 2009 (Studia Linguistica Germanica 100). 
Kommunikationsformen ${ }^{22}$; ebenso zu Räumen des Teufels wie etwa den Konfigurationen der Hölle als seinem Aufenthaltsort ${ }^{23}$. Für das Interesse des vorliegenden Bandes sind jedoch diejenigen, eher überschaubaren, Arbeiten besonders instruktiv, welche auf die teuflische Nähe zum Imaginären abheben $^{24}$ oder aber auf seine Fähigkeit fokussieren, im Menschen ein gewisses Selbst-Bewusstsein zu aktivieren, ${ }^{25}$ kommt doch hier bereits ein konstruktives Potential des Teufels zum Vorschein, ${ }^{26}$ welches die destruktiven und verschlagenen Seiten der Figur in den Hintergrund rücken lässt.

Der vorliegende Band sieht sich damit in der seit einigen Jahrzehnten wieder stärker in den Fokus geratenen kultur- und literaturgeschichtlichen Tradition, die Potentiale des Bösen, Hässlichen, Anderen und Abjekten, des Ausgegrenzten, Devianten und Queeren $\mathrm{zu}$ fokussieren und auf seine Funktionen $\mathrm{zu}$ befragen. ${ }^{27}$ Ein

\section{Z. B. bei Bockmann/Gold, Turpiloquium (Anm. 2).}

23 Vgl. DieTL, Cora: Himmel und Hölle. Das Infernum als narrativ entworfener Raum an der Wende zum 12. Jahrhundert. In: Neuphilologische Mitteilungen 115 (2014), S. 203-216; Jenseits eine mittelalterliche und mediävistische Imagination. Interdisziplinäre Ansätze zur Analyse des Unerklärlichen. Hrsg. von Christa TuCZAY, Frankfurt a. M. 2016 (Beihefte zur Mediävistik 21).

24 So beispielsweise bei Haug, Der Teufel und das Böse, S. 187 ff. (Anm. 9); Bergengruen, Maximilian: Macht der Phantasie/Gewalt im Staat. Zur diskursiven Verdopplung des Teufels in Grimmelshausens ,Simplicissimus‘. In: Simpliciana 26 (2004), S. 141-162, sowie DERS.: Der große Mogol oder der Vater der Lügen des Schelmuffsky. Zur Parodie des Reiseberichts und zur Poetik des Diabolischen bei Christian Reuter. In: ZfdPh 126/2 (2007), S. 161-184.

25 So bei RÖCKE, Werner: Das Subjekt und das Böse. Rituelle Abwehr und Verrechtlichung des Teufels als Formen der Subjektkonstitution im Spätmittelalter. In: Inszenierungen von Subjektivität in der Literatur des Mittelalters. Hrsg. von Martin BAISCH u. a., Königstein 2005, S. 288308. Ähnliches bei Flasch, Der Teufel, S. 28 (Anm. 2): „[f]erner kompliziert der Teufel psychologische Situationen und erhöht die Aufmerksamkeit auf diese. [. . .] Er macht neugierig; er fördert die Menschenkenntnis [. . .].“

26 Auch von „Kampf, Bewegung und Spannung“, die der Teufel in die Welt eingeführt haben soll, ist die Rede bei Flasch, Der Teufel, S. 28 (Anm. 2).

27 Als zentraler Prätext gilt RosenkRANZ, Karl: Ästhetik des Häßlichen, Königsberg 1853. Die neuere Forschung beschäftigt das Thema mindestens seit dem dritten Band der Reihe Poetik und Hermeneutik: Die nicht mehr schönen Künste. Grenzphänomene des Ästhetischen. Hrsg. von Hans Robert JAUß, München 1968 (Poetik und Hermeneutik 3); DERS.: Die klassische und die christliche Rechtfertigung des Häßlichen in mittelalterlicher Literatur. In: DERS., Die nicht mehr schönen Künste, S. 143-168 (Anm. 27); Eco, Umberto: Die Geschichte der Häßlichkeit. Aus dem Italienischen von Friederike Hausmann, München 2007; RöckE, Werner: Die Freude am Bösen. Studien zu einer Poetik des deutschen Schwankromans im Spätmittelalter, München 1987 (Forschungen zur Geschichte der älteren deutschen Literatur 6). Für die moderne Literatur vgl. grundlegend BRITTNACHER, Hans Richard: Ästhetik des Horrors. Gespenster, Vampire, Monster, Teufel und künstliche Menschen in der phantastischen Literatur, Frankfurt a. M. 1994, darin das Kapitel „Teufel. Die Versuchungen des Bösen“, S. 223-266, sowie ALt, Peter-André: Ästhetik des Bösen, München 2010. 
herausragendes Beispiel aus dieser neueren Richtung, das klare Affinitäten zum Teuflisch-Dämonischen aufweist, bildet die äußerst vielfältige Forschung $\mathrm{zu}$ Monstren und Erscheinungsformen des Monströsen. ${ }^{28}$ Auch die Queerund Intersektionalitätsforschung ist hier zu nennen, die sich teilweise mit Fragestellungen zum Monströsen überschneidet. ${ }^{29}$ Unser Band möchte dort angelegte Tendenzen aufgreifen und fortsetzen. Unter anderem war es den Herausgeberinnen wichtig, produktive Tendenzen des Teufels nicht nur mit Epochenschwellen in Verbindung zu bringen, wie es mit Blick auf seine Fähigkeiten, Ambivalenzen zu erschaffen und Individualität $\mathrm{zu}$ generieren, schon vielfach geschehen ist. ${ }^{30}$ Genauso sind umgekehrt den Tendenzen zur Dekonstruktion und Entmächtigung des Teufels in der Moderne ${ }^{31}$ seine zweifellos ebenfalls gegebenen Renaissancen entgegenzuhalten.

Uneindeutig und schwer fassbar ist der Teufel jedenfalls bereits in der mittelalterlichen Kultur - und dies häufig in ein und demselben Text: So konfrontiert etwa die Kurzerzählung Die Teufelsbeichte ${ }^{32}$ einen Teufel, der

28 Es seien nur einige Titel genannt: DASTON, Lorraine/PARK, Katharine: Wonders and the Order of Nature 1150-1750, New York 1998; CoHEN, Jeffrey Jerome: Of Giants. Sex, Monsters, and the Middle Ages, Minneapolis, London 1999 (Medieval Cultures 17); Asma, Stephen T.: On Monsters. An Unnatural History of our Worst Fears, New York 2009; KRAß, Andreas: Meerjungfrauen. Geschichten einer unmöglichen Liebe, Frankfurt a. M. 2010; SAX, Boria: Imaginary Animals. The Monstrous, the Wondrous and the Human, London 2013; SimeK, Rudolf: Monster im Mittelalter. Die phantastische Welt der Wundervölker und Fabelwesen, Köln, Weimar, Wien 2015; ebenso der Ausstellungsband: Monster. Fantastische Bilderwelten zwischen Grauen und Komik. Bearbeitet von Peggy GROßE/G. Ulrich Großmann/Johannes Pommeranz, Nürnberg 2015, der auch einen Einblick in die reiche visuelle Tradition gibt.

29 Vgl. etwa (De)formierte Körper. Die Wahrnehmung und das Andere im Mittelalter. «Corps (Dé)formés: Perception et l'Altérité au Moyen Âge.» Interdisziplinäres Seminar Straßburg, 19. März 2010. Hrsg. von Gabriela AnTunEs/Björn REICH, Göttingen 2012, sowie Gender Studies - Queer Studies - Intersektionalität. Eine Zwischenbilanz aus mediävistischer Perspektive. Hrsg. von Ingrid Bennewitz/Jutta EMInG/Johannes TRAULSEN, Göttingen 2019 (Berliner Mittelalter- und Frühneuzeitforschung 26).

30 Beispiele wären hier MÜLLER, Maria E.: Der andere Faust. Melancholie und Individualität in der Historia von D. Johann Fausten. In: DVjS 60 (1986), S. 572-608; MÜNKLER, Marina: Narrative Ambiguität. Die Faustbücher des 16. bis 18. Jahrhunderts, Göttingen 2011 (Historische Semantik 15), bes. Kap. 8 (S. 294-326); RöCKE, Die Freude am Bösen (Anm. 27).

31 Einen guten Überblick vermitteln BRITTNACHER, Hans Richard: „Satanismus“. In: Phantastik. Ein interdisziplinäres Handbuch. Hrsg. von DEMS./Markus MEY, Stuttgart 2013, S. 472-482, vor allem S. 475-482; sowie Teil 2 („Abbau“) der Untersuchung von FlASCH, der Teufel (Anm. 2).

32 In: Weltlohn, Teufelsbeichte, Waldbruder. Beitrag zur Bearbeitung lateinischer Exempla in mhd. Gewande nebst einem Anhang: De eo qui duas volebat uxores. Hrsg. und eingeleitet von 
verschiedene von Sünde gezeichnete Kirchenbesucher*innen beobachtet hat (Er gesach der vor so fleckig was, / Daz er nu was luter als ein glas), mit einem Priester im Beichtstuhl und zeichnet dabei eine äußerst zwiespältige Figur. Einerseits will der Teufel menschengleich sein und hofft auf die für den Menschen mögliche Gnade: Die gnade, die du hast gesehen, / Mochte auch daz an dir geschehen, / Daz du wurdest reine / Als dise lude gemeine [. . .]. Andererseits ist er nicht in der Lage, sich von seinen verschlagen-boshaften Impulsen zu lösen, die er in Aufzählung beinahe stolz beichtet, wobei er nicht willens ist, den religiös-rituellen Prozess auch bis zum Ende zu gehen: Hastu umb din sunde ruwen [. . .]? Der dufel sprach: ,Desn han ich niht [. . .]'. Zieht man für die Bewertung des hier auftretenden Teufels nicht allein die Handlung heran, sondern auch das Epimythion, so erregt der im deutlichen Willenskonflikt befindliche Teufel schlussendlich beinahe Mitleid. ${ }^{33}$ Denn das Ende der Kurzerzählung profiliert das Unvermögen des Teufels, aufrichtig bereuen und folglich Gnade erhalten zu können, weniger als individuelle Verfehlung der hier handelnden Figur. Vielmehr erscheint es als ein unausweichliches Gesetz seiner Gattung, diesen Konflikt in sich zu tragen, da jeder Teufel mit den Konsequenzen zu leben hat, die eine unwiderrufliche und jegliche Aussicht auf Heil verspielende Tat eines ihrer Artgenossen einst provoziert hatte: Wan daz heil amme dufel gar was verswunden [....] Und sint noch vil dufel die daz jehent, / Daz sie noch hoffenung sich versehent, / Daz doch so gar ist verlorn, / Wan sie hant verdientet godes zorn. In Anbetracht des allein in diesem Beispiel sichtbar werdenden Facettenreichtums ist es beinahe verwunderlich, wenn noch jüngste Publikationen zur Figur, in Irritation über die eigenen Befunde und offenbar in Widerspruch zu vorausgesetzten Teufelsbildern, notieren, dass der Teufel in der mittelalterlichen Kurzerzählung manchmal Rechts- sowie ethische und religiöse Normen vertritt und als

\footnotetext{
August Closs, Heidelberg 1934 (Germanische Bibliothek 37), S. 97-106; Zitate: V. 31/32 (,er sah, dass derjenige, der vorher so befleckt gewesen war, nun klar war wie ein Glas'), 33-36 (,die Gnade, die du gesehen hast; möge die auch an dir geschehen, so dass du rein würdest wie all diese Leute`); 209-211 (,'Bereust Du Deine Sünde?‘ Der Teufel sprach: ,Das tu ich nicht [. . . ]'), 220 (,Denn das Heil für den Teufel war ganz und gar verschwunden') und 225-228 (,Und gibt es noch viele Teufel, die das sagen, dass sie sich nach Hoffnung sehnen; doch ist das ganz und gar verloren, denn sie haben sich Gottes Zorn verdient').

33 Vgl. Gold, Julia: Mitleid mit dem Teufel? Ambivalenzen einer altbekannten Figur im geistlichen Spiel des Mittelalters und im protestantischen Drama der Frühen Neuzeit. In: Ambivalenzen des geistlichen Spiels. Revisionen von Texten und Methoden. Hrsg. von Jörn BockmanN/ Regina ToEPFER, Göttingen 2018 (Historische Semantik 29), S. 125-154.
} 
strafende Instanz agiert. ${ }^{34}$ Dabei ließe sich fragen, ob dem Teufel schon auf den Leim gegangen ist, wer ihm in Vorannahmen klar identifizierbare Motive und (stereo-)typische Emotionen zuschreibt und ihn solchermaßen vereindeutigt.

Viel naheliegender scheint es uns, kulturelle Wirkungen seiner Unverfügbarkeit zu entziffern. ${ }^{35} \mathrm{Um}$ es mit einem viel strapazierten Zitat $\mathrm{zu}$ sagen: Die Möglichkeit, dass der Teufel Teil ist einer „Kraft / die stets das Böse will und stets das Gute schafft“, ${ }^{36}$ ist für die Kultur und Literatur der Vormoderne noch auf größerem Maßstab zu überprüfen. Verschiedentlich wurde bereits darauf hingewiesen, dass der Teufel und seine Handlanger über ein „ästhetische[s] Surplus [verfügen ....], welches die Darstellung des Bösen bis heute interessanter und vielfältiger sein lässt als die des Guten“37. Oder mit Kurt FLASCH gesprochen und leicht anders akzentuiert: „Christentum mit Teufel macht Angst; Christenglaube ohne Teufel schmeckt fad.“"38 Die Fähigkeit des Teufels, geschickt „mit großer Macht [... .] und trügerische[n] Zeichen und Wunder[n]“ (2 Thess 2,9) umzugehen und so verschiedenste Illusionen zu befördern, könnte bedeuten, dass sich mit dem Transfer der Figur in einen literarischen Text auch diese teuflischen Merkmale übertragen und gestalterische Möglichkeiten des Wunderbaren wie Verwunderungswürdigen, Fiktionen oder auch Uneindeutigkeiten der Zeichen zunehmen. Hier scheint insbesondere das oft Staunen erregende Erscheinungsbild der Teufelsfiguren Möglichkeit zur kreativen Ausgestaltung zu bieten - etwa im Teufel, der einem Lindwurm gleich / [. . .] / am Bauch geel / weiß vnd schegget / vnd die Fluegel vnnd Oberthein schwartz / der halbe schwantz / wie

34 Vgl. KÖNNEKER, Barbara: Faust-Konzeption und Teufelspakt im Volksbuch von 1587. In: FS Gottfried Weber. Hrsg. von Heinz Otto BuRger/Klaus von SEe, Bad Homburg, Berlin, Zürich 1967 (Frankfurter Beiträge zur Germanistik 1), S. 159-213, hier S. 172, die eine ähnliche Inkonsistenz im sich dem Teufel mehr und mehr angleichenden Faustus beobachtet: „Faust, der dem Teufel Verfallene, kann im III. Teil gelegentlich sogar als Wächter über Tugend und christliche Gesinnung auftreten [. . .].“

35 Es sei denn, man versteht Kunst gleich als Form der Verfügbarmachung des Teufels, vgl. dazu SCHNYDER, Mireille: Die Verfügbarkeit des Teufels und die Kunst. In: UnVerfügbarkeit. Hrsg. von Ingrid KASTEN, Berlin 2012 (Paragrana 21/2), S. 47-59.

36 Johann Wolfgang Goethe: Faust. Texte. Herausgegeben von Albrecht ScHÖNE, Frankfurt a. M. 1994 (Johann Wolfgang Goethe: Sämtliche Werke I 7/1), V. 1336/1337. Zur Polyvalenz dieser scheinbar eingängigen Dialektik vgl. Johann Wolfgang Goethe: Faust. Kommentare. Von Albrecht SCHÖNE, Frankfurt a. M. 1994 (Johann Wolfgang Goethe: Sämtliche Werke I 7/2), S. 251.

37 BocKmann/Gold, Kommunikation mit Teufeln, S. 6 (Anm. 2).

38 FlASCH, Der Teufel, S. 28 (Anm. 2, Hervorhebung im Original). 
ein Schnecken Hauß / krumblecht / [ . . . ${ }^{39}$ auftritt. Doch beschränken sich die folgenden Untersuchungen keineswegs auf die vielfältigen und schillernden Masken des Teufels. Vielmehr ist es ihr Ziel, die ästhetische Dynamik, die sich rund um die Teufelsfigur in literarischen Texten entfaltet, in ihrer Komplexität aufzuzeigen und zu erfassen.

\section{Poietische Potentiale}

Der vorliegende Band möchte mit exemplarischen Lektüren zur erweiterten Perspektive hinsichtlich der literatur- und kulturgeschichtlichen Deutung des Teufels anregen und in verschiedenen Beiträgen die komplexe Nähe des Teufels zu kreativen anstelle von destruktiven Prozessen ausloten. Dabei ist nicht zu bestreiten, dass der Teufel auf der Ebene der Handlung zumeist die Rolle des Antagonisten einnimmt, in der er die Protagonist`innen auf ihrem Weg behindert oder die Welt des vermeintlich Guten zu zerstören trachtet. Die einzelnen Analysen unternehmen jedoch den Versuch, über diese stereotype Rollenzuweisung hinauszugehen. Dabei werden sie von der Annahme getragen, dass die weit verbreitete, über Jahrhunderte bis in die Gegenwart andauernde und verschiedenste Gattungen betreffende Integration einer Teufelsfigur in literarische Texte, in die bildende Kunst, in Theater und Film nicht möglich gewesen wäre, ${ }^{40}$ wenn sich mit ihr nicht auch ein beträchtliches Set an produktiven Energien verbinden würde. Vielfach scheint der Teufel in seiner Antagonistenrolle als Katalysator zu fungieren, um als Interaktionsfigur menschliche Emotionen, Sehnsüchte, Ängste, seelische Abgründe oder Machtgelüste zu Tage zu fördern und somit zu helfen, Verborgenes der Sichtbarkeit zuzuführen oder Unbewusstes in den Bereich des Bewusstseins zu rücken und so allererst zum Gegenstand einer (Ver-)Handlung zu machen.

Die im Folgenden versammelten Beiträge diskutieren verschiedene Szenen innerhalb der (überwiegend) vormodernen deutschen Literatur, die dem Teufel oder Phänomenen, die eine deutliche Beziehung zu ihm aufweisen, mehr oder auch minder viel (Erzähl-/Text-)Raum zugestehen. Ein Beitrag zur

39 Historia von D. Johann Fausten. In: Romane des 15. und 16. Jahrhunderts. Nach den Erstdrucken mit sämtlichen Holzschnitten. Hrsg. von Jan-Dirk MülLER, Frankfurt a. M. 1990 (Bibliothek der Frühen Neuzeit 1), S. 829-986, hier S. 857, Z. 7-11.

40 Einen Überblick über diese große Bandbreite vermitteln die Arbeiten von BRITTNACHER, vgl.: „Satanismus“ (Anm. 31), Ästhetik des Horrors, bes. S. 223-266 (Anm. 26). Außerdem Alt, Ästhetik des Bösen (Anm. 27). 
Teufelsfiguration in Gustave Flauberts berühmtem Roman Die Versuchung des heiligen Antonius macht die fortgesetzte Auseinandersetzung der Moderne mit dem christlichen Erbe deutlich, die in solcher Radikalität geführt wird, dass sie die Moderne als Projekt wieder in Frage $\mathrm{zu}$ stellen scheint. ${ }^{41}$ Immer ausgehend von einer detaillierten Beschreibung der Teufelsszenen kristallisieren sich dabei verschiedene, durchaus interdependente Felder heraus, innerhalb derer die Teufelsfigur poietische Potentiale entwickelt und so zur produktiven Störfigur avanciert.

(1) Wissen: Der Teufel provoziert und vermittelt ein Begehren nach Wissen. Das Wissen, das über den Teufel in literarischen Texten zugänglich wird, erweist sich jedoch, auf den ersten Blick betrachtet, meist als prekär ${ }^{42}$ : Es wird als verborgenes, gar verbotenes und demzufolge gefährliches Wissen inszeniert und denunziert. Doch verursachen gerade diese Verbote und Sanktionen, die es begleiten, zugleich seinen Reiz. Der Teufel übernimmt hier die Funktion eines zwiespältigen Pförtners. Er besitzt zwar den Schlüssel zu einer ganzen Welt von verbotenem Wissen und die Kenntnis von Techniken (z. B. Nekromantik oder Alchemie), sich bestimmtes Wissen anzueignen. Ebenso scheint er bereit, dieses Wissen mit dem Menschen zu teilen. Doch verlangt er dafür zugleich Gegenleistungen: in der Regel die Aufgabe der menschlichen Seele und somit auch der Aussicht auf ein ewiges Leben bei Gott. Am literarisch einflussreichsten hat diesen Tausch wohl die Historia von D. Johann Fausten inszeniert, die ihrerseits bereits auf verschiedene Teufelsbündnerlegenden zurückgreifen konnte. Auch die vielfältigen frühneuzeitlichen Abhandlungen über Hexen dokumentieren die Idee des problematischen Tauschgeschäfts. ${ }^{43}$ In diesen auf den ersten Blick paränetischen Texten wird das vom Teufel zur Verfügung gestellte Wissen zumeist als trügerisches klassifiziert, vor dem man sich folglich zu hüten hat. Dennoch machen die Texte eben dieses vermeintlich trügerische Wissen zum Thema und stellen seine

41 So die These von VinkEn, Barbara: Flaubert. Durchkreuzte Moderne, Frankfurt a. M. 2009 (ohne eingehendere Auseinandersetzung mit La Tentation de Saint Antoine).

42 Begriff nach Mulsow, Martin: Prekäres Wissen. Eine andere Ideengeschichte der Frühen Neuzeit, Berlin 2012, S. 14: „,Prekär` bedeutet unsicher, heikel, mißlich, problematisch, widerrufbar. Diese Qualifizierung betrifft nicht in erster Linie den Inhalt des Wissens, sondern seinen Status.“

43 Zur Fülle der Quellen in diesem Wissensbereich vgl. VoltMER, Rita: Wissen, Medien und die Wahrheit. Überlegungen zu Transferprozessen von ,Hexenwissen‘. In: Hexenwissen. Zum Transfer von Magie- und Zauberei-Imaginationen in interdisziplinärer Perspektive. Hrsg. von Heinz Sieburg/Rita Voltmer/Britta Weimann, Trier 2017 (Trierer Hexenprozesse Quellen und Darstellungen 9), S. 3-46. 
Geltung unter der Voraussetzung zur Diskussion, dass sie es an eine teuflische Figur binden. Vernachlässigt man die ethisch und religiös verwerflichen Implikationen, die mit den angebotenen Wissensinhalten einhergehen, lässt sich die Insertion eines Teufels in den Text in dieser Hinsicht als Strategie auffassen, nicht-kanonisches, verbotenes oder auch nur neues und noch nicht als solches etabliertes Wissen zur Geltung zu bringen (FuHRMANN, WEI). Dies birgt erheblichen Zündstoff: Denn dieses Wissen im Medium Literatur ist nicht nur individueller Lektüre anheimgestellt und in seinen Auswirkungen folglich schwer zu kontrollieren; ${ }^{44}$ es kann als literarischer Diskurs seinen engen Rahmen auch verlassen ${ }^{45}$ und Gegenstand außer-textueller Diskussionen und Praktiken werden. Die Gefahr, die sich hier auftut, manifestiert sich etwa in der Historia von D. Johann Fausten in der - zeitgenössisch üblichen - Entscheidung, die Zaubersprüche, mit denen Faustus den Teufel ruft, nicht mit abzudrucken. Die Teufelsfigur ist es, die diese prekären, da häufig neuen und bestehende Ordnungen überschreitenden Gedanken wie auch deren Manifestation provoziert und doch zugleich keinen sicheren Äußerungsraum garantiert. Und dennoch: Einmal als Möglichkeiten durchgespielt, sind diese Gedanken dank des Teufels als Wissen in der Welt - und es obliegt nun deren diegetischen wie extra-diegetischen Rezipient*innen, damit umzugehen.

(2) Individuation: In signifikantem Zusammenhang mit dem Teufel als Quelle eines in der Regel unzugänglichen Wissens lässt sich ein weiterer poietischer Aspekt der Figur festhalten. Indem sie nämlich den Menschen mit einem Angebot gegenübertritt, seien es Wissen oder Reichtum, Kunstfertigkeit oder Unterhaltung, stellt sie diese vor eine Wahl und eröffnet ihnen damit Raum, ihren von Gott gegebenen freien Willen auszuüben, die Konsequenzen daraus zu tragen und sich durch ihre Entscheidungen zu profilieren (BERGENGruen, Fuhrmann, Nowakowski, Wei). Eines der prominentesten Beispiele

44 Dies diskutiert für das Faustbuch im Kontext der breiten Literarisierungsbewegung in der Frühen Neuzeit HARTWEG, Frédéric: L'historie du Docteur FAUST ou des dangers du savoir et de la lecture. In: Sens et Etre. Mélanges en l'honneur de Jean-Marie Zemb. Hrsg. von Eugène FAUCHER/DEMS./Jean JANITZA, Nancy 1989, S. 93-102.

45 Mit literarischen und erzählenden Qualitäten des als juristischen Text konzipierten berüchtigten Hexenhammers (Heinrich Kramer [Institoris]): Der Hexenhammer. Malleus Maleficarum. Neu aus dem Lateinischen übertragen von Wolfgang BEHRINGER/Günter JEROUSCHEK/Werner TSCHACHER. Hrsg. und eingeleitet von Günter JEROUSCHEK/Wolfgang BEHRINGER, München ${ }^{9} 2011$, hat sich vor allem André SCHNydER auseinandergesetzt, vgl. SCHNyder, André: Formen und Funktionen des Erzählens in einigen dämonologischen Exempla des ,Malleus maleficarum“ (1487) von Institoris und Sprenger. In: Archivum Fratrum Praedicatorum 66 (1996), S. 257-292. 
dafür liefert wohl die Paradieserzählung der Genesis (Gen 2-3), die Stephen GREENBLATT gar als „Hymnus auf menschliche Selbstverantwortung“46 liest. Mag sich die freie Wahl letztlich auch - durch die Vertreibung aus dem Paradies oder einen anderen wol verdienten $\mathrm{Lohn}^{47}$ - sanktioniert finden; als Provokateur von Entscheidungen zeichnet die Teufelsfigur in einem ersten Schritt für soziale, kulturelle oder auch nur individuelle Dynamiken verschiedenster Art verantwortlich. Als Meister der Illusion fordert sie ferner kritische Urteilsfähigkeit, nötigt sie durch ihre Wandelbarkeit und ihren zwielichtigen Charakter doch beinahe konstant zur Einschätzung sowie Interpretation sich darbietender Sachverhalte. ${ }^{48}$

Neben diesen kognitiv-intellektuellen Leistungen kann die Teufelsfigur auch zu ganz konkreter physischer Aktivität und affektivem Engagement verführen, indem sie ihr Gegenüber zu einem Verhalten anstiftet, das aufgrund gesellschaftlicher Konventionen nicht statthaft ist. Das Mittelalter versteht solche Verhaltensweisen als Sünden, und literarische Texte des Mittelalters reizen den damit eröffneten Spielraum des Darstellungsmöglichen aus: So wird der Inzest, Inbegriff des Tabus, sowohl in der eher religiös als auch in der eher weltlichhöfisch geprägten Literatur regelmäßig auf das Wirken von Sathanas ${ }^{49}$ zurückgeführt. Das Thema der sexuellen Vereinigung unter teuflischer Beteiligung ermöglicht grundlegende Auseinandersetzungen mit der elitären Organisation adliger $^{50}$ oder auch Text-Familien (TRAULSEN, TSCHACHTLI) und konstituiert unterschiedliche Außenseiterprofile literarischer Heldinnen, die sich ihren sozialen Ort erst erobern und teilweise mit ihrer Verstrickung in Schuld konfrontieren müssen. Auch der Umstand, dass er als Einfallstor für die Ausarbeitung entsprechender Konflikte wirkt, begründet die poietische Macht des Teufels.

(3) Denken in Alternativen: Die Teufelsfigur als Generator von Wissen - ob über die Welt oder über das eigene Ich - ist nicht immer auch zugleich in der Verantwortlichkeit, die Wissensinhalte selbst beizusteuern. Ihre produktive

46 GreEnblatt, Stephen: Die Geschichte von Adam und Eva. Der mächtigste Mythos der Menschheit. Aus dem Englischen von Klaus BinDER, München 2018, hier S. 15.

47 Historia, Titelblatt, S. 831, Z. 8/9 (Anm. 39).

48 Vgl. BocKManN, Jörn: Turpiloquium Oder Wie handeln und sprechen die Teufel? Eine Relektüre von Strickers ,Richter und Teufel‘. In: DERS./GoLD, Turpiloqium, S. 21-44 (Anm. 2), hier S. 24 sowie 40/42.

49 https://www.zora.uzh.ch/id/eprint/17304/1/MaiundBeaflor-1.pdf, V. 784; Zugriff am 06. Juni 2020.

50 Dies ist prominent noch von Thomas Mann in seinen Adaptionen mittelalterlicher Stoffe, in Wälsungenblut und Der Erwählte, ironisiert worden. 
Funktion als Störelement kann ebenso darin liegen, die Möglichkeit einer Alternative aufzuzeigen oder eine Perspektivänderung anzuregen. Aus seiner tendenziell oppositionellen Positionierung heraus kann der Teufel Irritationen hervorrufen, die nicht allein destruktive Wirkung haben, sondern zugleich ein Innehalten provozieren und Reflexionsräume eröffnen, wo Regeln, Konventionen oder Gewohnheiten ein Denken in Alternativen häufig verunmöglichen und hinfällig erscheinen lassen. Die störende Teufelsfigur stellt so Mechanismen der Selbstverständlichkeit in Frage, sie bremst das Abspulen etablierter Muster Handlungs-, Verhaltens- oder auch Erzählweisen - aus und bricht es auf (MÜLLER). Bemerkenswert daran ist, dass offenkundig allein die durch den Teufel angedeutete Option einer Alternative von Bedeutung ist: Weder muss diese Möglichkeit, es auch anders zu tun, vom Teufel selbst ausgeführt werden, noch muss er einen alternativen Sinn, gewissermaßen als Lehrinhalt, anbieten; als Widerhak ${ }^{51}$, wie ihn Mechthilds von Magdeburg Fließendes Licht treffend bezeichnet, kann der Teufel auch ,bloß` den Denkanstoß liefern und anregen, dass es anders gehen könnte. Die Erzählinstanz berichtet hier von dem Leid, das ihr ein geistlich mensch [. . .] dur sine boesen sitten verursacht, deren Ursprung sich die Erzählerin nicht erklären kann. Gott gewährt ihr daraufhin eine Vision: Do sach ich, das ein sunderlich túfel dem menschen zuo hangete und zoh in wider von allen guoten dingen. Dieser besondere Teufel, der sich wenig später auf Nachfragen als Widerhak zu erkennen gibt, verführt den Menschen gerade nicht zu sündhaften Tätigkeiten; er lenkt nicht durch andere Reize vom geistlichen Leben ab. Widerhak bremst das als rechtmäßig interpretierte Verhalten lediglich aus, gebietet dessen nahezu automatischer Ausführung Einhalt. Einfallstor für das teuflische Wirken sei der menschliche muotwille, der sich sowohl für die falsche wie für die richtige Lebensweise entscheiden kann. Die Erscheinung des Teufels Widerhak im Fließenden Licht hält diese Entscheidungsfähigkeit des Menschen bewusst - nicht allein in seinem sprechenden Namen, sondern auch durch eine Erklärung, die der Teufel der Erzählinstanz gibt: Dem Menschen, also der ,bösen' Mitschwester, mag nieman helfen wan ir eigen muotwille, wan got hat ir den gewalt gegeben, das si iren sin mag umbekeren. Hier

51 Mechthild von Magdeburg: Das fließende Licht der Gottheit. Aus dem Mittelhochdeutschen übers. und hrsg. von Gisela VolLmanN-Profe, Frankfurt a. M. 2010, Buch VI, Kap. VII; S. 444, Z. 4/5 („[. . .] ein geistlicher Mensch [. . .] durch sein schlechtes Verhalten“); 8-10 („Da sah ich, wie ein besonderer Teufel diesem Menschen anhaftete und ihn hinweg zog von allen guten Dingen“); 20/21 (,[. . .] mag niemand helfen, nur ihr eigener freier Wille; denn Gott hat ihr die Gewalt darüber gegeben, dass sie ihre Gesinnung verändern kann.“). 
zeigt sich demnach zudem, was weiter oben über das Potential des Teufels als Beförderer menschlicher ,Individuation‘ ausgeführt wurde.

(4) (Un)Eindeutigkeiten: Mitunter ist es weniger der Aktionsradius, der sich mit der Teufelsfigur verbindet und ausdehnt, egal ob dieser Spielraum möglicher Handlungen effektiv genutzt und die verschiedenen, in ihm möglichen Tätigkeiten ausbuchstabiert werden oder ob er sich im Text bloß als eine Verheißung auftut. Dem Auftreten des Teufels kann im Hinblick auf das Denken in/von Alternativen auch ein Signalcharakter anhaften. Obwohl der Figur im Text nicht immer eine ausladende Präsenz zugestanden wird, fungiert sie kurz aufflackernd sozusagen - an kritischen Stellen als Markierung, und dort nicht etwa als eindeutige Kennzeichnung ,des Bösen“, sondern vielmehr als Signal für eine heikle Grenze. An dieser Stelle dann weist der Teufel Kippmomente aus, an denen legitimes in illegitimes Handeln umschlagen könnte. Doch scheint bemerkenswerterweise nicht die teuflische Figur selbst - oder zumindest nicht sie allein - den Ausschlag zur Illegitimität zu veranlassen. Vielmehr gibt sie lediglich die im Sachverhalt bereits angelegte, prekäre Uneindeutigkeit als solche zu erkennen. Als derlei ambiguisierender Fingerzeig lehrt der Teufel nicht allein ein Aspektsehen, sondern markiert Grenzziehungen im selben Moment, in dem er sie als permeabel und brüchig ausweist (MüLLER, TSCHACHTLI).

(5) Dynamik: Der Teufel impliziert folglich eine gewisse Agilität und Flexibilität, die mentaler wie physischer Natur ist. Gründend auf seiner Beweglichkeit, die sich im Gestaltwandel ebenso ausdrückt wie in seiner Volatilität, lässt sich die Figur als Verkörperung eines dynamischen Prinzips begreifen. Der Teufel vollzieht die räumliche Bewegung seiner ,Opfer' mit (NowAKOwsKI), wie es beispielsweise der stetige Ortswechsel der diabolischen Gestalten in der ZenoLegende demonstriert, ${ }^{52}$ oder verausgabt sich in rastloser Herausforderung des Wüstenvaters Antonius, dem er kontinuierlich neue ,Versuchungen“ anbietet (BRITTNACHER). Er scheut keinen Wirkungsbereich, begibt sich in alle denkbaren sozialen Felder und macht selbst vor dem Alltäglichen und Banalen keinen Halt. Insbesondere das Faustbuch hat auf Grund dieser Züge seines Helden Irritationen hervorgerufen - je ähnlicher Faustus dem Teufel wird und je mehr er Mimesis an dessen Zauberkräfte betreibt, desto banaler werden seine Interessen und Beschäftigungen: Sehr viele Episoden erzählen davon, dass Faustus stiehlt, betrügt, andere übervorteilt und aus keinem erkennbaren Grund

52 Zeno oder Die Legende von den heiligen drei Königen. Hrsg. von Anna ARFWIDSson, Lund 1940 (Lunder germanistische Forschungen 10). 
Schadenszauber ausübt, zum Beispiel indem er anderen ein Hirschgeweih auf den Kopf zaubert oder sich selbst einen riesigen Mund..$^{53}$ Ähnlich berichten die TeufelsErzählungen, die Caesarius von Heisterbach den Klosterbruder mit seinem Novizen erörtern lässt, neben schreckenerregenden Exempeln über Teufel, die den Menschen an Leib und Leben gehen, teils einfachste Streiche, z. B. zwischen Freunden Zwietracht zu stiften, ${ }^{54}$ Mönchen im Chor Gespenster erscheinen zu lassen $^{55}$ oder einen von ihnen während der Lesung zur Matutin dadurch zu ärgern, dass sie ihm die Kerze auspusten. ${ }^{56}$ Auch diese unentwegte diabolische Beweglichkeit lässt sich als Strategie zur Verweigerung von vereindeutigenden Maßnahmen interpretieren, als ein Hinweis auf eine jedem Sachverhalt innewohnende Vielschichtigkeit.

(6) Artistik/Virtuosität: Die Figur des Teufels zeigt häufig einen intensiven Bezug zu kunstvollen Ausdrucksformen wie beispielsweise zu geschliffener Rhetorik, Sprachwitz, Eloquenz und Schmeichelei. Es gehört nicht zu seinen geringsten kultur-literarischen Verdiensten, Sprachen der Verführung und des Begehrens zu generieren. ${ }^{57}$ Er hat eine starke Affinität zu Musik oder Tanz, ${ }^{58} z u$ deren Vollzug er auch die Menschen einlädt (EMING, FuHRMANN). Der Teufel beherrscht diese expressiven, artistischen Tätigkeiten, man denke

53 Zur Städtereise auf den Punkt gebracht von Mahlmann-Bauer, Barbara: Magie und neue Wissenschaften im Wagnerbuch. In: Religion und Naturwissenschaften im 16. und 17. Jahrhundert. Hrsg. von Kaspar vON GREYERZ u. a., Güterlsoh 2010 (Schriften des Vereins für Reformationsgeschichte 210), S. 141-185, hier S. 141: „Um nur dieses Wissen zu erlangen, hätte Faust sich nicht dem Teufel verschreiben müssen.“ Vgl. auch bereits die Einschätzung von KöNNEKER, Faust-Konzeption, S. 173 (Anm. 34): „[. . .] im übrigen zaubert Faust, wie es eben kommt, aus Ehrgeiz, Gefälligkeit, Bosheit oder aus bloßem Vergnügen. Es wäre ein sinnloses Unterfangen, hier Kapitel für Kapitel auf seinen tieferen Sinn hin zu befragen und zu der Grundidee des Werks in Beziehung setzen zu wollen." Vgl. jedoch auch den Ansatz von MATHES, Bettina: Verhandlungen mit Faust. Geschlechterverhältnisse in der Kultur der Frühen Neuzeit, Königstein/Taunus 2001, in Fausts teuflischen Künsten eine Vermittlung von Medienkompetenz zu sehen, bes. im Abschnitt „Der Simulationskünstler“, S. 131-141.

54 Vgl. Caesarius von Heisterbach: Dialogus Miraculorum. Dialog über die Wunder III. Lateinisch - Deutsch. Übersetzt und kommentiert von Nikolaus NöSGES/Horst SCHNEIDER, Turnhout 2009 (Fontes Christiani 86/3), Kap. 39, S. 1090-1093.

55 Vgl. Caesarius von Heisterbach, Dialogus, Kap. 48, S. 1114-1117 (Anm. 54).

56 Vgl. Caesarius von Heisterbach, Dialogus, Kap. 53, S. 1124/1125 (Anm. 54).

57 Vgl. dazu auch Eming, Dämonische Verführung (Anm. 15).

58 Und beschäftigt in dieser Hinsicht auch noch die moderne Literatur und Kultur, vgl. JANZ, Rolf-Peter: Sind Lachen und Tanzen gottlos? Heinrich Heine und Oskar Wilde. In: ,Gotteslästerung' und Glaubenskritik. Hrsg. von Hans Richard BRITTNACHER/Thomas KoEBNER, Marburg 2016, S. 73-85. 
etwa an die Implikation der Teufelssonate, derart virtuos, dass in der vollendeten Ausübung die Grenze zwischen übernatürlich inspirierter Kunst und seelenloser Perfektion mitunter zu verwischen scheint. Der Schritt von der Virtuosität zur sinnlosen Besessenheit, einer Mechanik gleich (BRITTNACHER), ist schnell vollzogen, wie folgende Darstellung eines (vermutlich) diabolisch zentrierten Tanzes im Simplicissimus Teutsch nahelegt:

diese tantzten einen wunderlichen Tantz / dergleichen ich mein Lebtag nie gesehen / dann sie hatten sich bei den Haenden gefast / und viel Ring ineinander gemacht [. . . ] und weil ein Ring oder Craiß umb den andern lincks / und die andere rechts herumb tantze / konte ich nicht sehen / wie viel sie solcher Ring gemacht / und was sie in der Mitten / darumb sie tanzten / stehen hatten. Es sahe eben greulich seltzam auß / weil die Koepff so possierlich durcheinander haspelten. Und gleich wie der Tantz seltzam war / also war auch ihre Music, auch sange / [ . . .] ein jeder am Tantz selber drein / welches ein wunderliche Harmoniam abgab [. . .] und wie dieser Tantz bald auß war / fieng die gantze höllische Gesellschaft an zu rasen / zu rufen / zu rauschen / zu brausen / zu heulen / zu wueten und zu toben / als ob sie alle toll und thoericht gewest waeren. ${ }^{59}$

Als Meister der Verwandlung, der unentwegt verschiedene Rollen spielt und eine Vielzahl von Masken sein eigen nennt, ist der Teufel überdies eine per se theatrale Erscheinung (EMING), die in der Illusion und dem ,Als Ob“ ihre Lebenswelt entwirft, an der sie auch die Menschen teilhaben lassen bzw. gar dazu anregen kann, es ihr gleich zu tun (MÜLLER).

Das konstante diabolische ,Als Ob“ kann sich zum literarischen Prinzip entwickeln, in ihrer Aussagekraft vielschichtige Texte hervorbringen, deren eigentliche Botschaft durch eine maskierende Oberfläche zunächst verdeckt ist (FuHRMAnN, TRAULSEN). In diesen Zusammenhängen fungiert die Teufelsfigur dann als poetologisches Signal, das, wie Jörn BocKMANN in seiner Analyse von Strickers Richter und Teufel gezeigt hat, ${ }^{60}$ für einen zusätzlichen, jedoch zum Offensichtlichen alternativen Sinn sensibilisiert. Neben dem Verweis auf multiple, manchmal zunächst verstellte Sinnschichten kann der Teufel auch die sprachliche Oberfläche von Texten affizieren, indem seine Tendenz zu kakophonem, a-rhythmischem Ausdruck ${ }^{61}$ sowie zur eher geräuschhaften Artikulation dazu genutzt wird, Sprache an ihre Grenzen der eindeutigen Signifikation

59 Hans Jacob Christoffel von Grimmelshausen: Simplicissimus Teutsch. Hrsg. von Dieter BREUER, Frankfurt a. M. ${ }^{4} 2015$ (Deutscher Klassiker Verlag 2), Buch II, Kap. XVII, S. 177, Z. 20-22; S. 177, Z. 27-S. 178, Z. 3; S. 178, Z. 17-20.

60 Siehe Bockmann, Turpiloquium (Anm. 48).

61 Vgl. SCHNEIDER, Almut: Teufelsklang und höllische Stille. Erzählen von Dissonanz im ,Wigalois‘ des Wirnt von Gravenberg. In: BockMAnN/GoLD, Turpiloquium, S. 83-103 (Anm. 2). 
zu treiben bzw. Gebiete auszuloten, die abseits der für die ,belles artes ‘üblichen Ausdrucksmodalitäten liegen (EMING), und demzufolge - ebenfalls in poetologischer Manier - auszustellen, wie suggestiv, ja manipulativ Sprache verfahren kann. ${ }^{62}$ In dieser Hinsicht kann die Integration einer Teufelsfigur in Texte dazu befähigen, das literarische Produkt verspielter, facettenreicher, komplexer, da mit maskiertem Sinn zu gestalten und den artistischen Spielraum voll auszuschöpfen: „Man“ kann, wie Walter HAUG formulierte, „,aus den diabolischen Möglichkeiten der menschlichen Einbildungskraft [. . . ] schöpfen, und es wird hier eine erste Ahnung davon spürbar, daß Dichten ein Sich-Einlassen auf den Teufel bedeuten kann. “63

In der Summe der im Folgenden versammelten Beiträge gewinnt diese schöpferische teuflische Kraft Kontur, und es zeigt sich eine Facette der so vielseitigen Figur, die bisher häufig hinter all ihren destruktiven Energien verborgen blieb: des Teufels poietische Macht.

\section{Die Marginalisierung der Fratze. Zum Tafelbild von Michael Pacher}

Dazu möchten wir abschließend noch kurz auf das Titelbild unseres Bandes eingehen (Abb. 1), das grundsätzlich eine eingehendere Betrachtung lohnt. Es handelt sich um ein Tafelbild, genauer, die Sonntagsseite des berühmten Pacher Altars, welche die Versuchung Christi darstellt. Der Tiroler Meister, Michael Pacher, fertigte den Altar, der noch heute in der Pfarr- und Wallfahrtskirche St. Wolfgang, Österreich, zu sehen ist, im letzten Viertel des fünfzehnten Jahrhunderts an. Die Alltagsseite des Klappaltars zeigt an der entsprechenden Position eine Szene, in welcher der Teufel versucht, eine Messe des Hl. Wolfgang durch Lärm zu stören, und die somit eine der Facetten des teuflischen Wirkens zur Geltung bringt, die, wie dargelegt, die Kulturgeschichte der Figur maßgeblich prägte: die Funktion als ewiger Störenfried und Unruhestifter insbesondere bei heiligen Handlungen, hier zusätzlich mit querulanten Tönen assoziiert.

62 Vgl. auch die vergleichende etymologisch-semantische Übersicht über die Wörter für das Böse bei RupPel, Antonia: Kakology. A Study of Some Evil Words. In: CHIGnell, Evil, S. 43-59 (Anm. 5).

63 Haug, Der Teufel und das Böse, S. 187 (Anm. 9). 


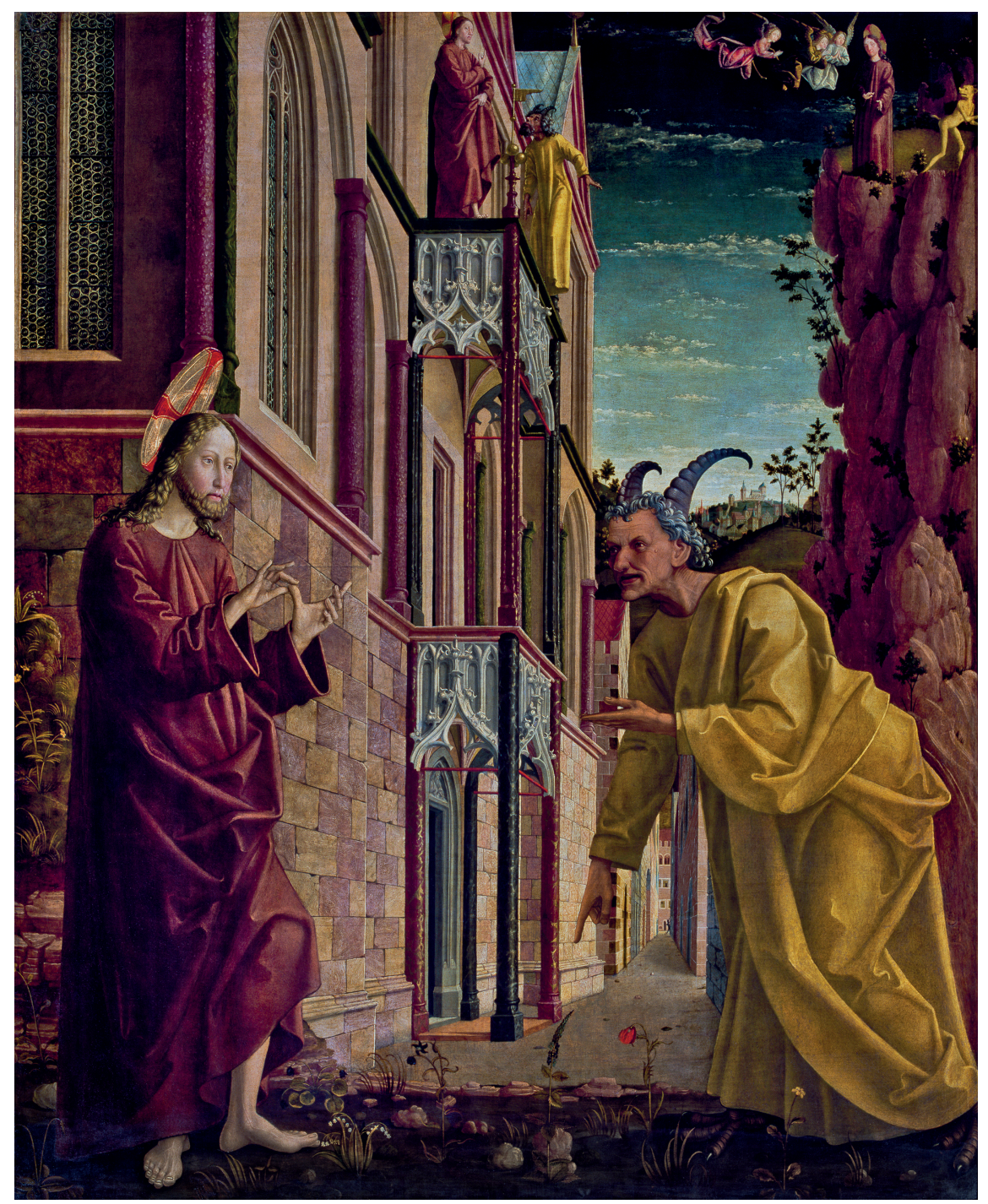

Abb. 1: Versuchung Christi (1480/82), Michael Pacher, Flügelaltar Sonntagsseite, St. Wolfgang/Österreich; Institut für Realienkunde - Universität Salzburg.

Während die Alltagsseite den Teufel demnach in einer seiner stereotypen Handlungen, dem Be- bzw. Verhindern von Heilsvermittlung, präsentiert, scheint die Konfrontation mit dem Teufel, welche die Sonntagsseite zeigt, komplexer angelegt. Das Bild hat mit der Versuchung Christi ein für die christliche Religion ungleich grundlegenderes Sujet, ja, eine Ur-Szene zum 
Darstellungsgegenstand gewählt, welche zentrale Imitatio Christi-Handlungen und -Narrative der christlichen Religion antizipiert. Die Evangelisten Matthäus (Mt 4,1-11) und Lukas (Lk 4,1-13) erzählen sie als Begegnung zwischen Jesus und dem Teufel in drei verschiedenen Sequenzen, die Pachers Bild dynamisiert und darin eine Transformation des teuflischen Wesens ausstellt, die insofern Aufsehen erregt, als hier weniger die Standhaftigkeit in Auseinandersetzung mit dem Teufel noch dessen Enthüllung als das fratzenhaft Böse in Gestalt eines geflügelten anthropomorphen Tierwesens im Zentrum zu stehen scheinen. Das monströs Teuflische verschwindet vielmehr in der Verkleinerung und ist an den Bildrand verbannt.

Im Bildvordergrund steht hingegen die erste von den Evangelien erzählte Begegnung, in welcher der Teufel den nach vierzigtägigem Fasten hungrigen Jesus auffordert, aus Steinen Brot werden zu lassen und damit unter Beweis zu stellen, dass er Gottes Sohn sei. Daraufhin antwortet Jesus, dass der Mensch nicht vom Brot allein, sondern auch vom Wort Gottes lebe. Während die Szene sich bei Matthäus und Lukas in der Wüste abspielt und damit paradigmatisch für ihre vormoderne Konzeptualisierung ein Ort der Prüfung wird, ${ }^{64}$ situiert Pacher sie vor der mittelalterlichen Kirche, die sich eng in den linken Bildraum schiebt und auf der rechten Seite von einer - weiter entfernten - Berganhöhe flankiert wird. Obwohl in der Bildmitte ein Horizont mit einer spätmittelalterlichen Stadt auf einem Hügel erkennbar wird, ist der Gesamteindruck der einer verengten Konzentration auf die Begegnung der beiden Protagonisten. Diese ist auf Grund ihrer optischen Angleichung, insbesondere wegen der Vermenschlichung des Teufels spektakulär. Obwohl es andere spätmittelalterliche Darstellungen von der Wüstenbegegnung gibt, in welchen der Teufel als Mönch erscheint (zum Beispiel von Simon Bening oder Juan des Flandes), ragt Pachers individualisierende Ausarbeitung gerade des Teufels heraus ${ }^{65}$ - und sie trifft sich zugleich mit den früher für diesen Band geltend gemachten Merkmalen: In einer sich Christus zuneigenden Körperhaltung sowie einer Geste seiner linken Hand, die weniger provozierend als elaborierend aussieht, erscheint der Teufel wie ein zugewandter Interaktionspartner im Gespräch, der mit der ausgestreckten und geöffneten Linken scheinbar gestisch zur Interaktion einlädt. Dabei verströmt er eine Aura von Intellektualität und Sensibilität, ja von Eleganz. Letzterer Eindruck entsteht insbesondere durch den Faltenwurf seines prächtigen Gewandes, das demjenigen von Christus

64 TRAULSEN, Johannes: Wüste, Wildnis, Einöde. In: Literarische Orte in deutschsprachigen Erzählungen des Mittelalters. Ein Handbuch. Hrsg. von Tilo Renz/Monika HanAuSKa/Mathias HERWEG, Berlin, Boston 2018, S. 598-606, hier S. 604.

65 Für wertvolle Hinweise danken wir Karin GLudovatz, Berlin. 
gleichwertig ist. Die grazil wirkenden Hände, welche durch die Zeigegeste betont werden, verweisen auf einen allein der geistigen Arbeit zugewandten Kleriker.

Gestützt durch den Hintergrund des Kirchenbaus entsteht so momentan der irritierende Eindruck zweier spätmittelalterlicher Theologen in einer scholastischen Erörterung. Zugleich jedoch ergehen in Form der über den grauen Locken sichtbaren Hörner und der unter dem Gewand hervorlugenden, allerdings in der Farbe des Erdbodens beinahe verschwindenden Krallenfüße Signale an die Betrachter^innen, dass die Vermenschlichung des Teufels trügerisch ist. Auch Christi Hautfarbe kontrastiert auffällig mit der seines Gegenübers und markiert damit die Grenzen ihrer Angleichung über das Medium des menschlichen Körpers. Das gelbe Gewand und die hässliche Zeichnung des Teufels-Gesichts, das eine hakenförmige Nase und Warzen aufweist, könnten zudem antijudaische Tendenzen vertreten; ob dies auch für die Bildkonventionen in Pachers Gemälde geltend $\mathrm{zu}$ machen ist, müsste im Rekurs auf weitere Belege erst noch verifiziert werden. Allerdings ist die Überblendung jüdischer und teuflischer Semantiken grundsätzlich für das Spätmittelalter nicht ungewöhnlich. ${ }^{66}$

Erst durch die im Bild in verkleinerter Form dargestellten weiteren zwei Begegnungen zwischen Jesus und dem Teufel entfaltet es seine bereits genannte Transformationsdynamik: links oben auf der Kirchenbrüstung und, noch weiter verkleinert, rechts oben auf dem Bergmassiv. Die Darstellung auf der Kirchenbalustrade vertritt die biblische Szene, in welcher Christus vom Teufel auf den Tempel in Jerusalem geführt wird und dort, den Angaben bei Matthäus und Lukas gemäß, von ihm aufgefordert wird, sich herabzustürzen. Jesus verweist daraufhin auf das Gebot der Heiligen Schrift, Gott nicht auf die Probe zu stellen. Die dritte Szene schließlich ereignet sich gemäß der Erzählungen im Neuen Testament auf einem Berg, auf den der Teufel Jesus führt, um ihm alle Reiche der Welt zu zeigen und ihm anzubieten, ihm diese zu übergeben, wenn Jesus sich ihm unterwerfe und bereit wäre, ihn anzubeten. Jesus begegnet diesem Verführungsversuch mit Gottes Gebot, ausschließlich diesem zu dienen. Im Evangelium des Lukas ist die Reihenfolge der zweiten und dritten Station vertauscht; die Bildlogik Pachers folgt Matthäus, dem zufolge Jesus den Teufel außerdem in der dritten Szene mit den Worten „Weg mit dir, Satan“ direkt adressiert (Mt 4,10).

Gerade diese Aufforderung ist es, welche die Szene am oberen rechten Bildrand bei Pacher vergegenwärtigt bzw. schon in ihrer Konsequenz zeigt: ${ }^{67}$ Der

66 Vgl. auch den Beitrag von Jutta Eming in diesem Band.

67 Dies wird gut nachvollziehbar über die Zoom-Funktion der Wiedergabe des Tafelbildes im Internet: https://upload.wikimedia.org/wikipedia/commons/f/f9/St._Wolfgang_kath._Pfarrkir che_Pacher-Altar_Versuchung_01.jpg; Zugriff: 06. Juni 2020. 
Teufel macht sich davon, und Jesus blickt ihm - mit einem auffällig herablassenden, beinahe angewiderten Blick - hinterher, während sein Körper sich bereits vom teuflischen Wesen ab- und stattdessen der Gemeinschaft der Engel zuzuwenden scheint. Das Wichtigste für den vorliegenden Zusammenhang ist dabei: Während Christus sich - abgesehen von der Modifikation in seiner Mimik - in allen drei Szenen äußerlich gleich geblieben ist, hat sich mit dem Teufel eine Metamorphose vollzogen, die in aller Deutlichkeit seine oben bereits angesprochene schillernde Vielgestaltigkeit herausstellt. Erst das letzte Bild zeigt ihn, trotz des immer noch menschlich-aufrechten Gangs, in der neutestamentlich geprägten satanischen Animalität, die Jesus direkt adressiert hatte und dessen Worte - das legt die Bildgestaltung nahe - damit performative Kraft entfalten: Das wahre Wesen des Teufels, die animalische Kreatur unter dem mönchischen Aussehen wird enthüllt. Aber bereits die zweite Begegnung zeigt als Zwischenstufe eine aufschlussreiche Wandlung der teuflischen Gestalt: Sie begegnet Christus nicht mehr auf gleicher Höhe, sondern ist perspektivisch verkürzt räumlich so unter ihm angeordnet, dass sie $\mathrm{zu}$ ihm aufsehen muss. An die Stelle der zugewandten Haltung des Bildvordergrunds ist eine zurückweichende Gestik getreten; das Gesicht hat sich bereits verwandelt, die vergrößerte Nase tendiert zum Fratzenhaften und die Gestalt trägt insbesondere durch den vermehrten Haarwuchs schon halb tierische Züge; der kunstvolle Faltenwurf des Gewands ist verschwunden, das Kleid hängt nun eher formlos am Körper herunter. Die (Rück-) Verwandlung des Teufels und der Verlust seiner Maskerade verhalten sich damit komplementär zur Standfestigkeit des mit sich selbst identischen Christus. Eben darin liefert die Pacher'sche Transformation des Teufels einen wunderbaren Beleg für das oben thematisierte ,ästhetische Surplus von Teufelsdarstellungen: Selbst dann, wenn sie die theologisch-ethische Schwäche des teuflischen Wesens ausweisen, setzen sie auf Abwechslung und wirken damit aufmerksamkeitsgenerierend sowie -lenkend.

Das Programm von Pachers Tafelbild ließe sich somit einerseits zwar durchaus als Narration einer erfolgreichen Begegnung mit dem Teufel bezeichnen: In dem Maße, in dem seine Masken durchschaut und seine Verführungsversuche abgewehrt werden, enthüllt er sein wahres Wesen und geht erfolglos ab. Auf der anderen Seite aber droht er buchstäblich eben gerade dann von der Bildfläche zu verschwinden, wenn sein boshafter Kern entdeckt und adressiert worden ist.

Es ist, so ließe sich folgern, weniger die - vielleicht als selbstverständlich vorausgesetzte - teuflische Monstrosität, die darstellungswürdig ist. Diese ist an den Rand des Bildes gedrängt, in immer stärkerer Verkleinerung als weniger wichtig ausgegeben und so auch der Aufmerksamkeit entzogen. Zwar deutet sie sich auch in den Hörnern und Krallenfüßen der Figur in der Bildmitte an, bleibt 
aber selbst dort eher marginal. Denn die Signale verlieren sich beinahe entweder in den blau-grauen Haaren sowie dem bläulichen Himmel oder aber im dunkelbraunen Erdboden. Der Teufel als das animalisch, fratzenhaft Böse wird so zwar aufgenommen, doch wesentlich ist die Auseinandersetzung mit ihm als der elaborierenden Gestalt. Pachers Bild verschiebt die Monstrosität nicht nur an den Rand und in die Verkleinerung, sondern er stellt die Verdrängung des Teufels - darauf wurde bereits hingewiesen - durch die drei Szenen deutlich als Prozess dar, von dem die Demaskierung und der Abzug erst den Schluss bilden. Die meiste Aufmerksamkeit erhält die zentral positionierte sowie beinahe die gesamte untere Bildhälfte einnehmende Gegenüberstellung der beiden als ebenbürtig inszenierten Figuren, wobei der Teufel hier sein Gegenüber durch die zugewandte Körperhaltung, Zeigegesten und Blickkontakt deutlich zur eingehenderen Auseinandersetzung mit sich herauszufordern scheint.

Das Tafelbild bringt demnach weniger eine Faszination für die bestandene Prüfung zum Ausdruck als vielmehr für die Handlungen und Erscheinungen, die den Weg dorthin prägen; das Resultat hat zwar Bedeutung, doch steht definitiv sein prozessuales Entstehen im Zentrum der Aufmerksamkeit. Der Teufel interessiert nicht als Überwundener, sondern als Sparrings-Partner. Mit diesem Reiz am Teufel - der Faszination für die Auseinandersetzung mit ihm und weniger für den Sieg über ihn - kalkuliert auch das Lukasevangelium. Denn Lukas beendet die Beschreibung der dritten Begegnung zwischen Jesus und dem Teufel mit dem nahezu dichterischen Kunstgriff der Suspense. Der Teufel verschwindet. Zumindest vorerst. Der Evangelientext nämlich platziert einen Hinweis, dass der Teufel fortan „bis zur bestimmten Zeit“ (Lk 4,13) von Versuchungen Jesu abgelassen habe. Diese temporale Einschränkung eröffnet die Perspektive auf die perennierenden Anstrengungen des Teufels, nicht nur Jesus, sondern alle Gläubigen anzufechten. Umgekehrt ergeht an diese die An- und Aufforderung, die teuflischen Verkleidungen und Täuschungen bestenfalls zu durchschauen und ihnen standzuhalten - sich in jedem Fall aber in der einen oder anderen Weise mit dem Teufel auseinanderzusetzen. So beinhaltet die auf den Evangelientexten fußende Darstellung der Versuchung Christi eine Andeutung der sich potentiell fortsetzenden, unendlichen Varianten einer Konfrontation mit dem Teufel, und Pachers Kunstwerk eröffnet damit die Perspektive auf die Geschichten des vorliegenden Bandes. 